\title{
Site effect evaluation in Sellano, Italy, by 1-D and 2-D numerical analyses
}

\author{
P. Capilleri ${ }^{1}$, G. Lanzo ${ }^{2}$, M. Maugeri ${ }^{1}$ \& A. Pagliaroli ${ }^{2}$ \\ ${ }^{I}$ Department of Civil and Environmental Engineering, \\ University of Catania, Italy \\ ${ }^{2}$ Department of Structural and Geotechnical Engineering, \\ University of Rome "La Sapienza", Italy
}

\begin{abstract}
The 1997-1998 Umbria-Marche seismic sequence induced severe damage to the historical centre of Sellano (Perugia, Italy). During the long aftershock sequence, two temporary accelerometric stations, about $300 \mathrm{~m}$ apart, provided several ground motion records. These data allowed the investigation of the amplification of surface motion which can essentially be ascribed to local seismic effects. A site response study of the historical centre of the village was carried out by means of 1-D and 2-D numerical analyses to clarify the role played by the stratigraphic and topographic effects. The applicability of 1-D and 2-D models was examined by comparing the recorded and calculated acceleration response spectra. 1-D response analyses seem to indicate a significant stratigraphic effect on the ground response. Conversely, 2-D response analyses have shown only moderate amplification effects due to surface topography, which somewhat improved the predictions of site response spectra.
\end{abstract}

Keywords: 1997 Umbria-Marche earthquake, stratigraphic effects, topographic effects, $1-D$ and 2-D numerical analyses.

\section{Introduction}

It is well recognised that local seismic effects can exert a significant influence on the distribution of damages during earthquakes. Traditionally, these effects have been studied by means of simple one-dimensional (1-D) models of seismic wave propagation, which take into account only the influence of the stratigraphic profile and soil/bedrock properties on the seismic response. Conversely, local effects 
derived from surface topography such as ridge and cliffs, which are typically two-dimensional (2-D) problems, have received less attention because of the lack of experimental data and the need of more refined models. It is therefore of great interest to quantitatively evaluate the relative contribution to seismic response of stratigraphic as well as topographic effects, which can be very different depending on the specific morphological conditions and geotechnical characteristics at the site.

This can be particularly important in Italy, where several historical towns are built on top of crests or hills and therefore they could be susceptible of significant topographic amplification.

In the present work, a site response study, which refers to the historical town of Sellano, is presented. The study has been conducted using two temporary accelerometric stations, which have recorded a significant number of aftershocks of the 1997-1998 Umbria-Marche seismic sequence. Computed and recorded responses were compared to assess whether 1-D analyses are adequate for evaluating the seismic response at Sellano. Several 2-D analyses were also carried out to see what the effects of topography may be and to investigate whether 2-D models provide a better simulation of site response. These issues are discussed by comparing response spectra of recorded motions with those obtained from ground motions calculated by 1-D and 2-D analyses.

\section{Morphological and geological description of the site}

The village of Sellano is located in the Umbrian Apennines, central Italy, about $45 \mathrm{~km}$ east of Perugia and $120 \mathrm{~km}$ northeast of Rome (fig. 1). The village stands on a hillcrest elongated approximately in the WE direction, at about $640 \mathrm{~m}$ above the sea level. The ancient town is located on the eastern border of the hill while the most recent expansion area (from 1800 onwards) develops at its western portion. The morphology is characterized by steep slopes, as it can be seen in fig. 1 where two schematic cross-sections, traced respectively across the historic centre $\left(\mathrm{A}-\mathrm{A}^{\prime}\right)$ and the newer area $\left(\mathrm{B}-\mathrm{B}^{\prime}\right)$, are depicted.

From the geological point of view, the study area is made of the "Scaglia" unit constituted of alternating layers of limestones and marly limestones embedded in a sandy-silt or clayey-silt matrix [1]. The "Scaglia" unit may be further differentiated into four sub-units, i.e. the "Scaglia Bianca", "Scaglia Rossa", "Scaglia Variegata" and "Scaglia Cinerea". The calcareous levels are prevalent in the oldest units ("Scaglia Bianca" and "Rossa") while the marly-clayey levels predominate in the youngest ("Scaglia Variaegata" and "Cinerea"). Sellano is mainly constituted of the "Scaglia Cinerea" formation, which is weathered in the upper part and frequently covered by fill material of variable thickness.

\section{Historical seismicity and the 1997-1998 Umbria-Marche seismic sequence}

The Sellano area is characterized by significant historical seismicity that produced extensive damages to the village. 

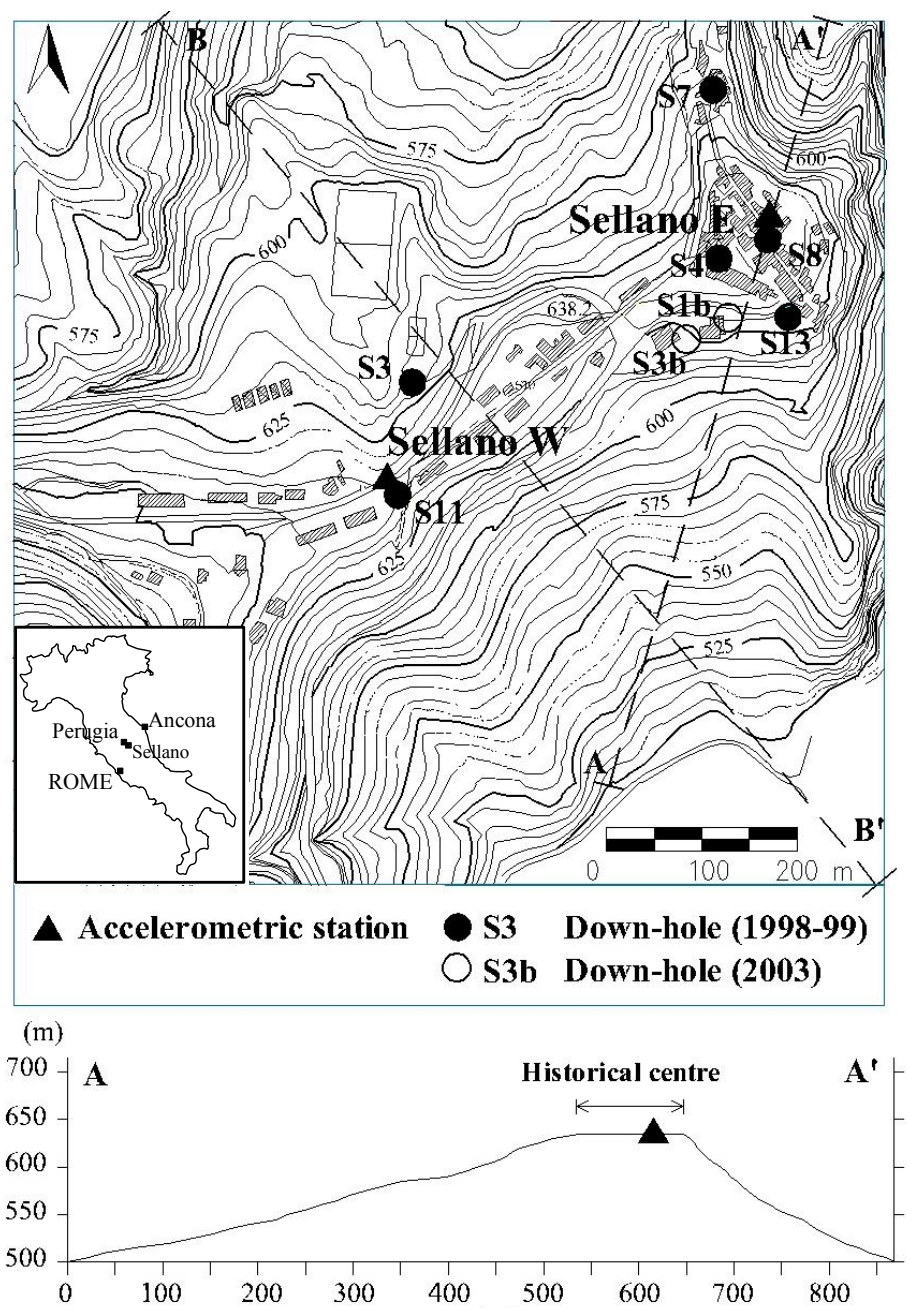

(m)

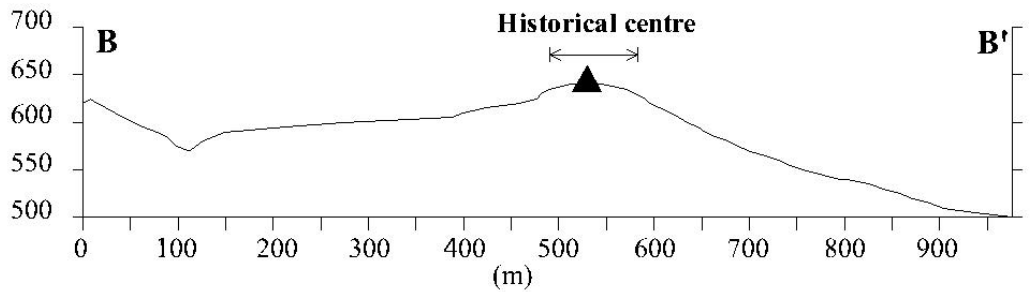

Figure 1: (Top) Plain view of the Sellano area with location of down-hole tests and accelerometric stations; (bottom) schematic cross-sections $\mathrm{A}-\mathrm{A}^{\prime}$ and $\mathrm{B}-\mathrm{B}^{\prime}$. 
The seismic catalogues show numerous earthquakes with intensity ranging between VII and X degree on the Mercalli-Cancani-Sieberg (MCS) scale [2]. Among the principal seismic events having epicenter within $9 \mathrm{~km}$ from Sellano, it is worth remember the December 4, $1328\left(I_{0}=\mathrm{X} \mathrm{MCS}, M_{\mathrm{m}}=6.5\right.$ estimated $)$ and the February $14,1838\left(I_{0}=\right.$ VIII MCS, $M_{\mathrm{m}}=5.5$ estimated $)$ earthquakes. The most important recent events are the 19 September, 1979, Valnerina earthquake $\left(M_{\mathrm{s}}=5.5\right)$ and the 29 April, 1984, Gubbio earthquake $\left(M_{\mathrm{s}}=5.3-5.5\right)$.

The Umbria-Marche seismic sequence occurred between September 1997 and April 1998 along a seismogenetic structure constituted of several faults with essentially NW-SE direction [2]. The sequence started on September 3, 1997, at 22.07 GMT, with an earthquake of magnitude $M_{\mathrm{L}}=4.4$ localised in the Colfiorito area, about $20 \mathrm{~km}$ north of Sellano. The first strong event of magnitude $M_{\mathrm{L}}=5.5$ occurred on September 26, at 00:33 GMT, followed at 09:40 GMT by another strong quake with magnitude $M_{\mathrm{L}}=5.4$. The epicenters of both earthquakes were located around Colfiorito. The successive seismic activity was characterised by smaller events with epicenters migrating towards the southern part of the tectonic structure, i.e. the area of Sellano. On October 14, 1997, another strong event $\left(M_{\mathrm{L}}\right.$ $=5.4$ ) occurred, with epicenter at about $2.5 \mathrm{~km}$ north of Sellano, which produced severe damage ( $I=$ VIII-IX MCS) to the historical buildings of Sellano.

\section{Accelerometric data}

After October 14, 1997, the Servizio Sismico Nazionale (SSN) installed at Sellano two accelerometric stations located in the historic center and in the newer expansion area and hereafter called Sellano East and Sellano West respectively (fig. 1). The aftershocks recorded by both stations in the period November 1997-April 1998 are listed in table 1. Most of the aftershocks occurred very close to the village, at an epicentral distance $(D)$ of less than $10 \mathrm{~km}$ and at depth $(d)$ not greater than about $6 \mathrm{~km}$; the local magnitude ranges between 3.1 and 4.5.

Table 1: Aftershocks recorded by Sellano East and Sellano West stations [3].

\begin{tabular}{|c|c|c|c|c|c|c|c|c|c|c|c|}
\hline$\#$ & Date & Time & $\mathbf{d}$ & $\mathbf{M}_{\mathbf{L}}$ & $\mathbf{D}$ & $\#$ & Date & Time & $\mathbf{d}$ & $\mathbf{M}_{\mathbf{L}}$ & $\mathbf{D}$ \\
\hline 1 & $8 / 11 / 97$ & $15: 31.54$ & 6.4 & 4.3 & 5.6 & 8 & $21 / 03 / 98$ & $16: 45: 9.6$ & 5.0 & 4.5 & 6.8 \\
\hline 2 & $30 / 11 / 97$ & $11: 24.42$ & 4.0 & 4.0 & 8.2 & 9 & $22 / 03 / 98$ & $13: 02: 24.6$ & 5.0 & 2.4 & 7.3 \\
\hline 3 & $1 / 12 / 97$ & $22: 37: 50$ & 3.3 & 2.9 & 6.6 & 10 & $23 / 03 / 98$ & $04: 30: 52.8$ & 5.6 & 3.6 & 7.5 \\
\hline 4 & $2 / 12 / 97$ & $09: 20: 45.9$ & 1.7 & 3.1 & 6.9 & 11 & $23 / 03 / 98$ & $09: 24: 11$ & 6.0 & 2.1 & 7.6 \\
\hline 5 & $7 / 02 / 98$ & $00: 59: 44.8$ & 3.1 & 4.3 & 14.8 & 12 & $26 / 03 / 98$ & $16: 26: 17$ & 4.7 & 4.7 & 29.7 \\
\hline 6 & $16 / 02 / 98$ & $13: 45: 19.2$ & 6.8 & 2.8 & 10.6 & 13 & $03 / 04 / 98$ & $07: 26: 36$ & 1.4 & 5.0 & 36.1 \\
\hline 7 & $24 / 02 / 98$ & $12: 32: 14.2$ & 5.4 & 3.1 & 10.1 & 14 & $05 / 04 / 98$ & $15: 52: 20$ & 5.4 & 4.5 & 36.8 \\
\hline
\end{tabular}

$\mathrm{d}=$ depth $(\mathrm{km}), \mathrm{D}=$ epicentral distance $(\mathrm{km})$

In fig. 2, the response acceleration spectra (5\% damping) of the NS component of the horizontal motion recorded in both stations during some selected seismic events listed in table 1 (i.e. \#1,\#2,\#4 and \#7) are compared. The spectral ordinates referring to Sellano East are always higher than those corresponding to Sellano 
West, particularly in the range of structural period $T=0.15-0.25 \mathrm{~s}$. These evident differences in the records can be attributed to local seismic effects, considering that for both stations the contribution of the earthquake source and travel path should be the same. Analogous considerations have been made by Sanò and Pugliese [4] and, more recently, by Natale and Nunziata [5].
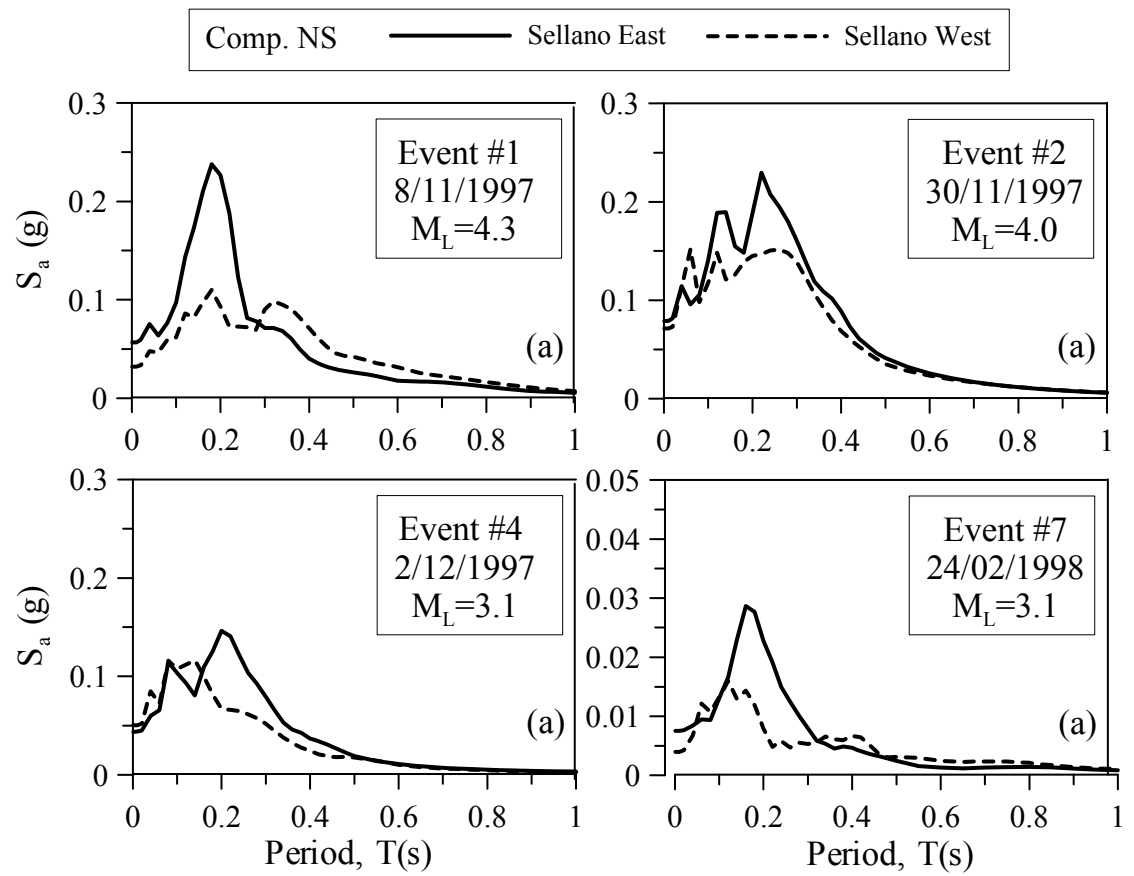

Figure 2: Response acceleration spectra of NS horizontal component recorded at both accelerometric stations (Sellano East and Sellano West) during four aftershocks of the 1997-1998 Umbria-Marche seismic sequence.

\section{Geotechnical characterisation of the subsoil for seismic response analyses}

A comprehensive geotechnical investigation was conducted in the most damaged area between November 1998 and November 1999 [6] and additional field and laboratory tests were carried out in January 2003 [7]. With special reference to the dynamic material properties, the overall investigation program consisted of downhole tests for the determination of shear $\left(V_{\mathrm{S}}\right)$ and compressional $\left(V_{\mathrm{P}}\right)$ wave velocity profiles as well as laboratory tests on undisturbed samples. The laboratory program comprised dynamic (resonant column) and cyclic (torsional shear and simple shear) tests for the measurement of stiffness and damping properties of the silty-clayey soils of the "Scaglia Cinerea" formation [7]. 
In fig. 2 the $V_{\mathrm{S}}$ and $V_{\mathrm{P}}$ values versus depth are plotted, as determined in the boreholes S8 (fig. 2a) and S11 (fig. 2b), respectively, close to the accelerometric stations Sellano East and Sellano West. With reference to the $V_{\mathrm{S}}$ profiles, in fig. $2 \mathrm{a}$, it is possible to identify a shallow layer of fill material down to $4 \mathrm{~m}$ depth with $V_{\mathrm{S}}=180 \mathrm{~m} / \mathrm{s}$, the weathered "Scaglia Cinerea" between 4 and $11 \mathrm{~m}$ depth characterised by $V_{\mathrm{S}}=400 \mathrm{~m} / \mathrm{s}$ and the unweathered "Scaglia Cinerea", down to a depth of $25 \mathrm{~m}$, with $V_{\mathrm{S}}$ variable between 500 and about $900 \mathrm{~m} / \mathrm{s}$. Experimental results at borehole $\mathrm{S} 11$ show a slightly stiffer site, characterised by $V_{\mathrm{S}}$ values between $500 \mathrm{~m} / \mathrm{s}$ and $700 \mathrm{~m} / \mathrm{s}$ from 7 to $15 \mathrm{~m}$ depth. The $V_{\mathrm{P}}$ values are about $600-700 \mathrm{~m} / \mathrm{s}$ in the fill material, $1300-1400 \mathrm{~m} / \mathrm{s}$ in the weathered "Scaglia Cinerea" and 1700-1900 m/s in the underlying unweathered Scaglia. The downhole tests of the 2003 field campaign were carried out in the shallowest materials, down to $7 \mathrm{~m}$ depth, and essentially confirm the above $V_{\mathrm{S}}$ and $V_{\mathrm{P}}$ data.

It is interesting to note that the fundamental period of the soil column for the Sellano East site is approximately $0.2 \mathrm{~s}$, which is very close to the period at which peak spectral amplification occurred in the recorded motion (fig. 2).

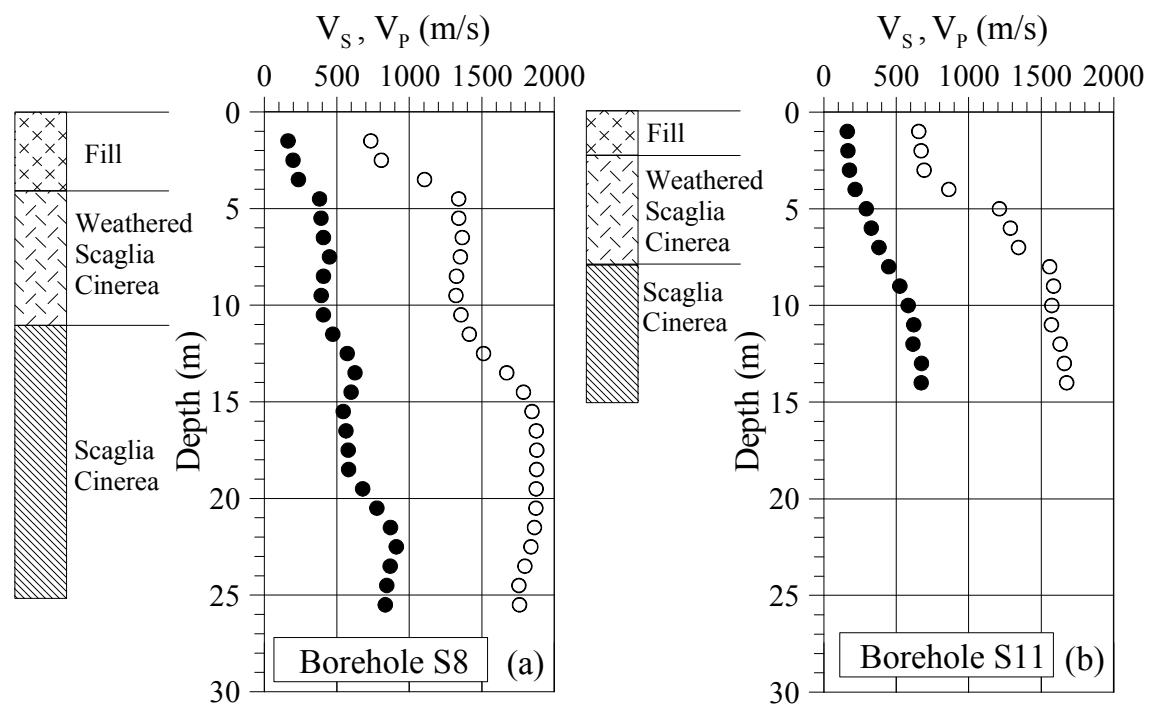

Figure 3: Stratigraphy and wave velocity $\left(V_{\mathrm{P}}\right.$ and $\left.V_{\mathrm{S}}\right)$ versus depth in (a) S8 and (b) S11 boreholes, respectively close to Sellano East and Sellano West accelerometric stations.

\section{1-D and 2-D seismic response analyses}

Among the aftershocks simultaneously recorded by both accelerometric stations Sellano East and Sellano West, seismic response analyses have been performed for two of them, i.e. the events \#2 and \#4 (table 1). In particular the NS horizontal component of the accelerograms recorded at Sellano West was used as input excitation to study the seismic response of Sellano East. The input excitation was 
defined in terms of "rock outcrop" accelerogram, calculated by a 1-D deconvolution analysis of the recorded ground surface motion. The deconvolution was carried out by the computer code Proshake [8], on the hypothesis of linear soil behaviour, using an idalised $V$ s profile based upon the down-hole test results in fig. $3 b$.

To investigate the role of soil stratigraphy on the amplification of seismic motion, a 1-D analysis for the Sellano East site with Proshake was carried out first. The soil deposit consisted of four layers resting on elastic bedrock. The physical (unit weight $\gamma$ ) and mechanical ( $V_{\mathrm{S}}$ and the small-strain damping ratio $D_{0}$ ) parameters of the 1-D geotechnical model are listed in table 2. The decrease of normalized shear modulus and the increase of soil damping with strain amplitude for each layer were obtained from laboratory measurements for the weathered "Scaglia Cinerea" and from well-established empirical data for the other materials.

The results of the 1-D analyses are illustrated in figs. $4 \mathrm{a}$ and $4 \mathrm{~b}$, referring to the seismic events \#2 and \#4 respectively, where the comparison between computed and recorded motion at Sellano East is confined to acceleration response spectra (5\% structural damping). In the same figures, for convenience, the response spectra of the recorded motion at Sellano West and of the corresponding deconvoluted motion on bedrock outcrop (input motion) are also showed. From both figures it can be seen that a significant amplification of the input motion occurs, especially in the period range between 0.15 and $0.25 \mathrm{~s}$, which roughly corresponds to the fundamental period of soil deposit. In fact the 1-D seismic analyses correctly identify the period of peak response for event \#2 and a secondary peak for event \#4. The computed spectra are slightly lower than the recorded ones for event \#2 while a greater discrepancy occurs for event \#4, at least at the period of peak response. At very short periods $(T \approx 0.05 \mathrm{~s})$ the response is underestimated for event \#2 while it is perfectly matched for event \#4.

Table 2: Main parameters defining the 1-D and 2-D geotechnical models.

\begin{tabular}{|c|c|c|c|c|c|c|}
\hline Layer & $\begin{array}{c}\text { Depth } \\
(\mathbf{m})\end{array}$ & $\begin{array}{c}\gamma \\
\left(\mathbf{k N} / \mathbf{m}^{\mathbf{3}}\right)\end{array}$ & $\begin{array}{c}\mathbf{V}_{\mathbf{S}} \\
(\mathbf{m} / \mathbf{s})\end{array}$ & $\begin{array}{c}\mathbf{D}_{\mathbf{0}} \\
\mathbf{( \% )}\end{array}$ & $\begin{array}{c}\mathbf{V}_{\mathbf{P}} \\
(\mathbf{m} / \mathbf{s})\end{array}$ & $\mathbf{v}$ \\
\hline 1 & $0-4$ & 18.7 & 180 & 2.0 & 650 & 046 \\
\hline 2 & $4-11$ & 19.4 & 400 & 1.20 & 1330 & 0.45 \\
\hline 3 & $11-20$ & 20 & 600 & 1.20 & 1620 & 0.42 \\
\hline 4 & $20-70$ & 21 & 900 & 0.4 & 1980 & 0.37 \\
\hline bedrock & $>70$ & 22 & 1200 & 0.4 & 2500 & 0.35 \\
\hline
\end{tabular}

To further explore the influence of the hill morphology on the surface motion, a 2-D numerical investigation was also performed using the FEM code QUAD4M [9]. The A- $\mathrm{A}^{\prime}$ cross section, approximately oriented NS direction, was used to back analyse the seismic response. A deformable bedrock was assumed while the lateral boundaries of the mesh were adequately extended horizontally to minimise the effects of wave reflections. As for the material properties, the values of compressional wave velocity, $V_{\mathrm{P}}$, and Poisson ratio, $v$, are also indicated in table 2 for the definition of the 2-D geotechnical model. 


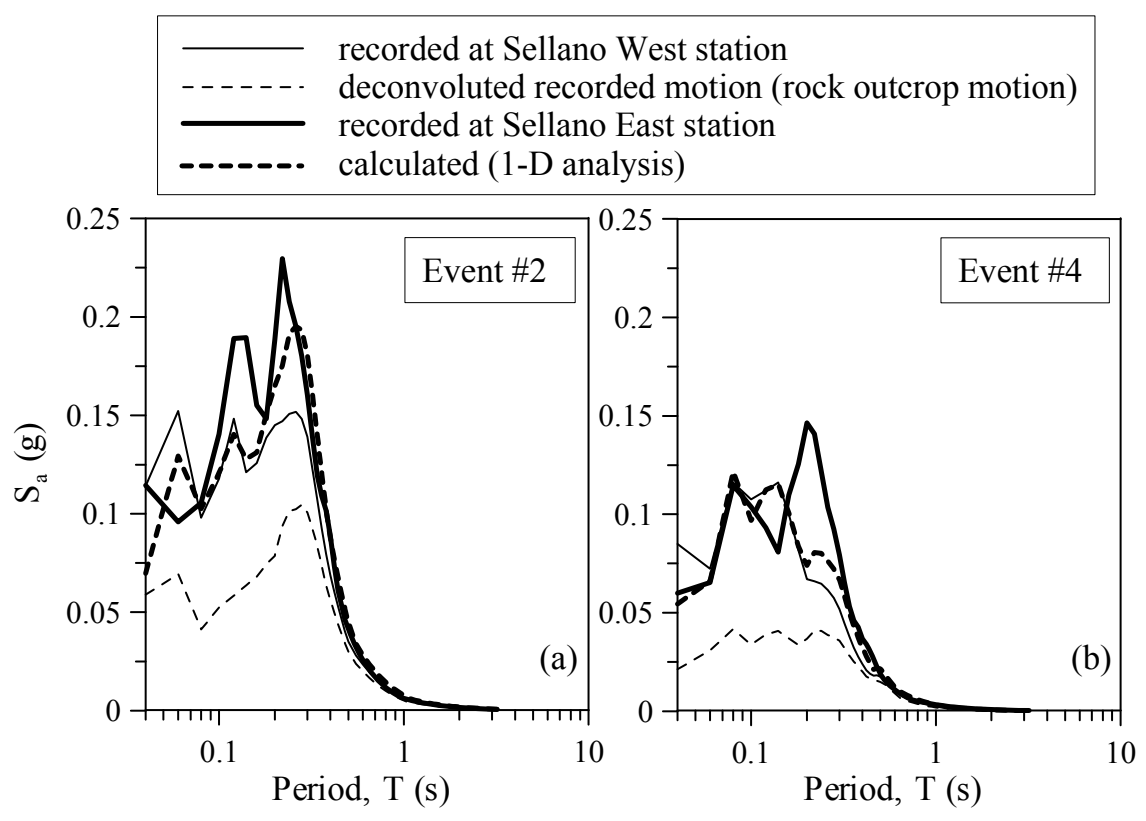

Figure 4: Comparison of recorded and calculated response spectra from 1-D seismic response analyses.

Comparison between computed (1-D and 2-D) and recorded acceleration response spectra is illustrated in figs. $5 \mathrm{a}$ and $5 \mathrm{~b}$ for the seismic events \#2 and \#4 respectively. As for the 2-D analyses, the response spectra are calculated in five selected surface points located approximately close to Sellano East. It can be observed in the figures that, for event \#2, 2-D response fairly accurately model the peak spectral response with the 2-D spectral ordinates being always higher that the 1-D peak response; conversely, deamplification of motion can be noted at lower periods ( $T<0.15 \mathrm{~s}$ ) with respect to the 1-D response. The results for event $\# 4$ show a different pattern, in that the 2-D response in the selected points is generally lower than the 1-D response, with a significant underestimation at very low periods $(T \approx$ $0.05 \mathrm{~s}$ ). Further, 2-D analyses do not substantially modify the period of peak response with respect to 1-D analyses.

From the above results it can be concluded that the seismic response of Sellano East is prevalently controlled by stratigraphic amplification while the effect of surface topography leads only to a minor adjustment of spectral peak response (event \#2) or to variations in spectral ordinates or in the period of peak response which do not significantly improve the prediction of response spectra (event \#4) with respect to $1-\mathrm{D}$ results. 


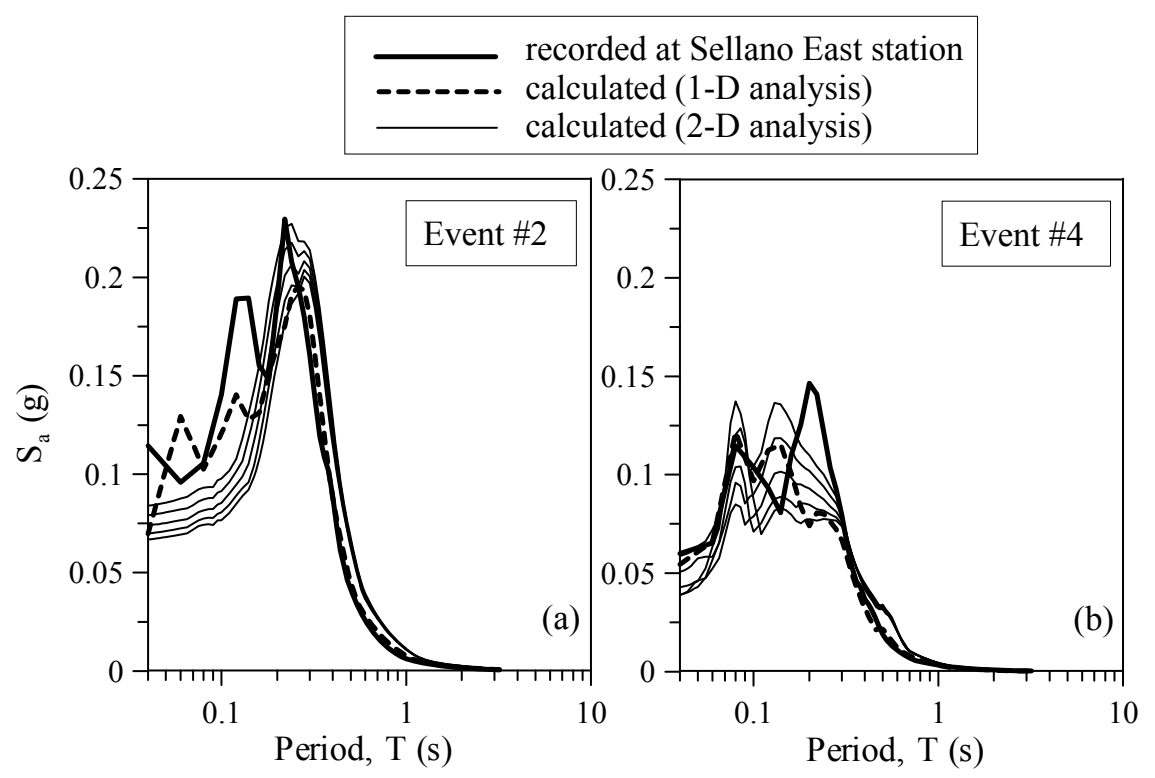

Figure 5: Comparison of recorded and calculated response spectra from 1-D and 2-D seismic response analyses.

\section{Conclusions}

The comparison of ground motions recorded at two temporary accelerometric stations installed in Sellano by the Servizio Sismico Nazionale during the 1997-1998 Umbria-Marche seismic sequence showed significant amplification effects in the range of periods $0.15-0.25 \mathrm{~s}$, especially dangerous for masonry structures. A numerical study of seismic response has been carried out with the purpose of comparing the recorded and computed acceleration response spectra. 1-D and 2-D numerical codes were used to separately account for soil stratigraphy and topographic effects.

It has been shown that 1-D response analyses can justify the appreciable observed amplification of surface motion and can provide a good indication of the period of peak response, which is mainly associated with the fundamental period of the site. The 2-D analyses did not significantly modify the seismic response, neither in terms of periods of peak response nor in terms of spectral amplitudes, even if they improved somewhat the predictions of site acceleration spectra.

Further study should be conducted by performing parametric analyses to investigate the sensitivity of response to the geometrical and geotechnical model parameters and by assuming a range of input motions statistically more significant. These data, once available, should be sufficient to clarify the role played by surface topography and to provide more robust validation of the seismic response at Sellano. 


\section{References}

[1] Guadagno, F.M. \& Magaldi, S., Sellano: the complex subsoil beneath an old hill town in Umbria. Rivista Italiana di Geotecnica, 4, pp. 53-63, 2001.

[2] Decanini, L., Mollaioli, F. \& Oliveto, G., Structural and seismological implications of the 1997 seismic sequence in Umbria and Marche, Italy. Innovative Approaches to Earthquake Engineering, ed. G. Oliveto, WIT Press: Southampton, Boston, pp. 229-323, 2002.

[3] The Umbria-Marche sequence Strong Motion Dataset (September 1997-June 1998). CD Rom. Servizio Sismico Nazionale. Roma, 2002.

[4] Sanò, T. \& Pugliese, A., Parametric study on topographic effects in seismic soil amplification. Earthquake Resistant Engineering Structures II, eds. C.A. Brebbia \& G. Oliveto, WIT Press: Southampton, Boston, pp. 321-330, 1999.

[5] Natale, M. \& Nunziata, C., Spectral amplification effects at Sellano, Central Italy, for the 1997-98 Umbria seismic sequence. Natural Hazards, 33, pp. 365-378, 2004.

[6] Cavallaro, A. \& Maugeri, M., Dynamic characterization of soils at Sellano for seismic microzonation. Rivista Italiana di Geotecnica, 4, pp. 70-78, 2001.

[7] Capilleri, P., Caratterizzazione Geotecnica e Microzonazione Sismica della Città di Sellano, Tesi di Dottorato in Ingegneria Geotecnica, Università degli Studi di Catania, 2003.

[8] EduPro Civil System, Inc., ProShake Ground Response Analysis Program, EduPro Civil System, Inc., Redmond, Washington, 1998.

[9] Hudson, M., Idriss, I.M. \& Beikae, M., QUAD4M: a computer program to evaluate the seismic response of soil structures using finite element procedures and incorporating a compliant base, Department of Civil and Environmental Engineering, University of California Davis, 1994. 